\title{
An Empirical Study: The Mediated Effect of Team Identification, Team Negative Affectivity and Team Cohesion
}

\author{
Zheng Huang ${ }^{1, a,{ }^{*}}$ \\ ${ }^{1}$ Macau University of Science and Technology, Avenida Wai Long, Taipa, Macau \\ ahuangzheng1989@aliyun.com \\ ${ }^{*}$ Corresponding author
}

\begin{abstract}
Keywords: Abusive supervision climate, Team task performance, Team identification, Team negative affectivity, Team cohesion.
\end{abstract}

\begin{abstract}
In this study, we propose and test a mediation model to explore the effect of team identification, team negative affectivity and team cohesion on abusive supervision climate and team task performance. Using a sample of 48 dyads of employees and their immediate supervisors from nineteen companies and two industries in China, we find that there is a negative relationship between abusive supervision climate and team task performance. Moreover, the results indicate that team identification, team negative affectivity and team cohesion mediate the relationship between abusive supervision climate and team task performance. Theoretical and practical implications, limitations, and future research directions are discussed.
\end{abstract}

\section{Introduction}

In this study, we investigate a potential explanation for why abusive supervision variability influences work outcomes, examine the relationship between abusive supervision variability and the task performance, and interpret the mediation on team identification, team negative affectivity and team cohesion.

Prior researchers have investigated how that abusive supervision negatively influences various organizational outcomes. However, the antecedents and psychological mechanisms of abusive supervision are not well understood, especially in the Chinese context. In recent years, organizational researchers have devoted substantial attention to harmful behaviors perpetrated by individuals who hold positions of authority within organizations [16].

In particular, research on abusive supervision [13] has grown rapidly over the past decade. Abusive supervision refers to "subordinates" perceptions of the extent to which supervisors engage in the sustained display of hostile verbal and nonverbal behaviors, excluding physical contact [13]. The study indicates that abusive super-vision can be quite detrimental to an organization and its employees in the form of decreased employee commitment, job performance, organizational citizenship behaviors, and increased psychological distress, depression, work-family conflict, counterproductive behaviors, and turnover [5, 6, 13].

However, little attention has been paid to identifying the mediators of abusive supervision and team task performance [2, 7, 15]. Through a better understanding of when and why abusive supervision develops, researchers can identify ways to minimize the occurrence and it is destructive consequences.

Our paper complements and expends the existing research that focuses on testing the relevance of a dispersion-based conceptualization of unit level abusive supervision such as Tepper et al. (2006), who found that supervisors were more abusive toward subordinates who were high versus low on negative affectivity, and Harris et al. (2011), who have also found that supervisors tend to be abusive only toward subordinates with whom they have poor quality relationships with individuals who have also been associated with low performance [6]. Following from the preceding discussion, we hypothesize that:

Hypothesis 1: $\quad$ Abusive supervision climate will negatively relate to team task performance.

Hypothesis 2: $\quad$ Team identification will mediate the relationship between abusive supervision climate and team task performance.

Hypothesis 3: Team negative affectivity will mediate the relationship between abusive supervision climate and team task performance. 
Hypothesis 4: Team cohesion will mediate the relationship between abusive supervision climate and team task performance.

The rest of paper is organized as follows. The next section describes research methods, including the research questionnaire design, questionnaires distribution for three times, and measures of each variable and controls. The third section analyzes the data in the part of results, and then verifies assumptions. Finally, we discuss our findings and conclusions.

\section{Method}

\section{Sample and Procedure}

The sample consists of 48 dyads of employees and their immediate supervisors $(\mathrm{N}=192)$ from nineteen companies and two industries in China, Participants are private enterprises employees, mostly they are office workers and product developers and their respective supervisors. Two hundred and ten complete and usable questionnaires were returned, representing $87 \%$ response rate. The final sample of 167 respondents can be described as follows: 62.2 percent were male, the mean average age was thirty four, the mean organizational tenure of 11 years, and subordinates were predominantly married ( 86.2 percent). The workers obtained a mean of 15 years of education. Among the immediate supervisors, 64.7 percent were male, the mean age was 35 years, and the mean organizational tenure was 8 years. They had a mean of 19 years of education.

According to Mitchell and James (2001), surveys were administered at three points in time to provide the most rigorous test of the hypotheses. The Time 1 survey included measures of abusive supervision climate and demographic variables. The demographic information included age, gender, marital status, organizational tenure, working hour, position, and nature of a job. The Time 2 survey included measures of the mediating mechanisms (i.e., team negative affectivity, team identification, and team cohesion). The Time 3 survey included the dependent variable, team task performance. The timing was purposeful.

\section{Measures}

Along with the results of Cronbach's alpha calculations for the various measures, the following measures were translated from English into Chinese and then back translated into English by two independent bilingual individuals to ensure equivalency of meaning. When a measure is described as having dimensions, the dimensions (items averaged) were used as indicators for their construct in structural equation modeling (described under "Analysis"). Otherwise, items were averaged into an overall scale score.

The control variables, in order to control the employee and supervisor in the demographic and personal potential impact on employees, include the age, sex and dyad tenure, academic staff, in charge of education, supervisor subordinate staff, competent in the job and so on. Among them, the employee and supervisor subordinate employees age in accordance with the actual number, the rest of the virtual digital instead. For example: in charge of education and academic staff (College $=15$, University $=16$, graduate student $=18$ ); supervisor position in the company (director $=0$, middle managers $=1$, senior manager $=2$, the company level manager $=3$ ). In view of the impact of abusive supervision climate on team identification, and consistent with team task performance research in the Chinese context, we controlled for several demographics in the moderation and mediation regression that examined the team identification and team negative affectivity. A single item was used to measure the demographic characteristics of gender (Male $=0$, Female $=1)$, marital status (Single $=0$, Married =1), age at last birthday, years of formal education, and number of years worked with the organization.

\section{Data Analysis}

\section{Confirmatory Factor Analyses}

According to pervious literatures [8], a two-step process of analysis with AMOS 21.0 employed to test our hypotheses. In the first step, we used tests to verify the distinctiveness of the five variables in this study. In the second step, we used a model comparison procedure to evaluate our structural models. 
To confirm the operationalization of the five variables (i.e., abusive supervision climate, team negative affectivity, identification, cohesion and task performance), we conducted a confirmatory factor analysis using AMOS 21.0. We compared the baseline model with a single-factor model and three two-factor models; the baseline model produced a significant improvement in chi-squares, suggesting a better fit than the single-factor or two-factor models [12]. In addition, all the changes in CFIs between the baseline model and others were greater than 0.01 , which suggests a better fit of the baseline model [8]. The results are presented in Table 1.

As shown, the baseline five-factor model fitted the data well $\left(\chi^{2}=409.43, \mathrm{p}<0.01\right.$; $\mathrm{df}=160$; root-mean-square error of approximation $($ RMSEA $)=.07$; comparative fit index $(\mathrm{CFI})=.86$, The Tucker-Lewis coefficient $(\mathrm{TLI})=.83$ ) .

Against this baseline five-factor model, we combined variables and tested five alternative models. Given the high correlations among abusive supervision climate, identification, negative affectivity, and team cohesion, we tested three four-factor models in which other mediators remained separate factors while abusive supervision and one of them were combined into one factor. We find that all of them demonstrated unsatisfactory fit and did not fit as well as the hypothesized model $\left(\chi^{2}=409.43, \mathrm{p}\right.$ $<0.001 ; \mathrm{df}=164 ; \mathrm{RMSEA}=.09 ; \mathrm{CFI}=.86, \mathrm{TLI}=.83$ ).

Then, we tested a three-factor model in which abusive supervision climate and task performance remained separate factors while the mediating mechanisms were combined into one factor. This model demonstrated unsatisfactory fit as well as poorer comparative fit than the hypothesized model $\left(\chi^{2}=707.47, \mathrm{p}<0.01 ; \mathrm{df}=167 ; \mathrm{RMSEA}=.14 ; \mathrm{CFI}=.69 ; \mathrm{TLI}=.64\right)$.

Finally, we tested a two factor model in which we combined abusive supervision climate and three mediation factors. The model also demonstrated unsatisfactory fit and did not fit as well as the hypothesized model $\left(\chi^{2}=871.15, \mathrm{p}<0.01 ; \mathrm{df}=169 ; \mathrm{RMSEA}=.16 ; \mathrm{CFI}=.59\right.$; TLI $\left.=.54\right)$. Thus, we treated our five variables as discriminant in all subsequent analyses.

Tab.1 Comparison of measurement models

\begin{tabular}{|c|c|c|c|c|c|c|c|}
\hline Model & Factor & $\chi^{2}$ & $\mathrm{df}$ & $\Delta \chi^{2}$ & RMSEA & CFI & TLI \\
\hline Baseline & Five factor & 409.43 & 160 & -- & 0.07 & 0.86 & 0.83 \\
\hline Model1 & $\begin{array}{l}\text { Four factor: abusive supervision } \\
\text { climate and team identification are } \\
\text { combined into one factor. }\end{array}$ & 554.97 & 164 & $\begin{array}{c}145.54 \\
* *\end{array}$ & 0.12 & 0.77 & 0.74 \\
\hline Model2 & $\begin{array}{l}\text { Four factor: abusive supervision } \\
\text { climate and team negative affectivity } \\
\text { are combined into one factor. }\end{array}$ & 588.85 & 164 & $\begin{array}{c}179.42 \\
* *\end{array}$ & 0.13 & 0.75 & 0.71 \\
\hline Model3 & $\begin{array}{l}\text { Four factor: abusive supervision } \\
\text { climate and team cohesion are } \\
\text { combined into one factor }\end{array}$ & 645.77 & 164 & $236.34 * *$ & 013 & 0.68 & 0.72 \\
\hline Model4 & $\begin{array}{l}\text { Three factor: team identification, } \\
\text { team negative affectivity, and team } \\
\text { cohesion are combined into one } \\
\text { factor. }\end{array}$ & 707.47 & 167 & $298.04 * *$ & 0.14 & 0.69 & 0.64 \\
\hline Model5 & $\begin{array}{l}\text { Two factor: abusive supervision } \\
\text { climate, team identification, team } \\
\text { negative affectivity, and team } \\
\text { cohesion are combined into one } \\
\text { factor. }\end{array}$ & 871.15 & 169 & $461.72 * *$ & 0.16 & 0.59 & 0.54 \\
\hline
\end{tabular}

\section{Descriptive Statistics and correlation}

The descriptive statistics and zero-order correlations of the study variables are shown in Table 2, which presents the means, standard deviations, reliability coefficients, and zero-order correlations of all the studied variables. Perceptions of abusive supervision climate correlated significantly $(\mathrm{p}<.01)$ with team identification and team cohesion $(r=-.23$ and .27 , respectively) and abusive supervision climate are negatively related to team task performance $(r=-.02, p<.05)$. 
Tab.2 Descriptive Statistics and Correlations

\begin{tabular}{|c|c|c|c|c|c|c|c|c|c|c|c|c|c|c|}
\hline Variables & mean & S.D & 1 & 2 & 3 & 4 & 5 & 6 & 7 & 8 & 9 & 10 & 11 & 12 \\
\hline Gender & 0.66 & 0.51 & 1 & & & & & & & & & & & \\
\hline Age & 29.10 & 6.27 & $-.16^{*}$ & 1 & & & & & & & & & & \\
\hline Education & 15.33 & 2.69 & $-.18 *$ & .09 & 1 & & & & & & & & & \\
\hline Marital & 0.38 & 0.51 & -.11 & .03 & $.22 * *$ & 1 & & & & & & & & \\
\hline Tenure & 5.28 & 5.09 & .01 & $.75 * *$ & .004 & -.01 & 1 & & & & & & & \\
\hline Stenu & 2.94 & 2.48 & -.05 & $.60 * *$ & -.04 & .04 & $.71 * *$ & 1 & & & & & & \\
\hline Hour & 41.34 & 12.50 & .13 & .15 & -.05 & -.08 & .12 & $.17 *$ & 1 & & & & & \\
\hline Abusive & 1.81 & 0.87 & .07 & -.01 & $-.21 * *$ & -.05 & .02 & .03 & .01 & 1 & & & & \\
\hline Identification & 3.52 & 0.77 & -.08 & -.10 & .07 & -.03 & -.15 & $\begin{array}{l}.14 \\
\end{array}$ & $-.23 * *$ & $-.39 * *$ & 1 & & & \\
\hline Negative & 1.98 & 0.90 & .09 & $-.16^{*}$ & $-.24 * *$ & -.10 & -.06 & -.13 & .07 & $.54 * *$ & $-.35 * *$ & 1 & & \\
\hline Cohesion & 3.72 & 0.82 & -.03 & -.08 & -.14 & -.06 & -.02 & -.01 & $-.27 * *$ & $-.36 * *$ & $.68 * *$ & $-.32 * *$ & 1 & \\
\hline Performance & 3.77 & 0.68 & -.04 & $-.21 * *$ & -.13 & .001 & $-.17 *$ & $-.17 *$ & $-.02 *$ & -.14 & $.17 *$ & $.16^{*}$ & $.19 *$ & 1 \\
\hline
\end{tabular}

\section{Hypothesis tests (SEM)}

The univariate correlation between abusive supervision climate and team task performance $(\mathrm{r}=.02$, $\mathrm{p}<.05)$ provided preliminary evidence to support Hypothesis 1 , which states that abusive supervision climate has positive relationship with team task performance. For Hypothesis2, 3 and 4, we examined the main and mediated effects of abusive supervision climate and team identification on team task performance. The results are presented in Table 3.

The model 1 is our baseline model and represents a fully mediating model. We first specified a direct effect model in which abusive supervision climate predicted team task performance. This model does not have direct paths from abusive supervision climate to followers' task performance. As Table 3 shows, all fit indexes showed a good fit $\left(\chi^{2}=478.26, p<0.01 ; \mathrm{df}=164\right.$; RMSEA $=.08$; CFI $=.82, \mathrm{TLI}=.89$ ). Against our baseline model, we tested the nested model. In model 2, we specified a partial mediation model in which we added the indirect effects of team identification, team negative affectivity, and team cohesion.

We then compared the partial mediation model to a mediation model in which we specified a null direct effect between abusive supervision climate and team task performance. This full mediation model, wherein the effect of abusive supervision climate on team task performance is specified through the indirect effects of team identification, team negative affectivity, and team cohesion- also demonstrated excellent fit and was not significantly different from the partial mediation model $\left(\chi^{2}=\right.$ 472.04, $\mathrm{p}<0.01 ; \mathrm{df}=163$; RMSEA $=.11 ; \mathrm{CFI}=.82$, TLI $=.79)$. Under the principle of model parsimony, these results suggested that model 1 better fitted our data. We concluded the path coefficients from the full mediation model, given its increased parsimony.

Accordingly, we shows that the coefficient of the path from abusive supervision climate to team identification, team negative affectivity and team cohesion was significant $(\beta=-.29, .53$, and -.42 , respectively, $\mathrm{p}<.01$ ), as were the coefficients of the paths from team identification, team negative affectivity and team cohesion to task performance $(\beta=-.27,-.45$, and .33 , respectively, $p<.05)$. However, the substantial path between abusive supervision climate and task performance $(\beta=-.30)$ suggested that abusive supervision climate negatively influences supervisory ratings of employee task performance.

Tab.3 Comparison of Structural Equation Models

\begin{tabular}{|c|c|c|c|c|c|c|}
\hline Model and Structure & $\chi^{2}$ & df & $\Delta \chi 2$ & RMSEA & CFI & TLI \\
\hline $\begin{array}{c}1:+ \text { team negative affectivity }+ \text { team cohesion }->\text { team task } \\
\text { performance }\end{array}$ & 478.26 & 164 & -- & 0.08 & 0.82 & $\overline{0.89}$ \\
\hline $\begin{array}{l}\text { 2: abusive supervision climate }->\text { team identification }+ \text { team } \\
\text { negative affectivity }+ \text { team cohesion }->\text { team task performance; } \\
\text { and abusive supervision climate } \rightarrow>\text { team task performance }\end{array}$ & 472.04 & 163 & $-6.22 *$ & 0.11 & 0.82 & 0.79 \\
\hline
\end{tabular}




\section{Discussion}

\section{Findings and Contributions}

This study examines the conceptual and empirical links between abusive supervision climate and team task performance. These findings are consistent with the notions that: (1) abusive supervision climate are negatively related to team identification, and the team negative affectivity mediate this relationship between abusive supervision climate and team task performance; (2) team identification mediates the relationship between abusive supervision climate and team task performance of employees. Team identification and team cohesion then had a negative influence on team task performance. The results reveals that abusive supervision climate and employees' team negative affectivity play active role in employee' team task performance during the process they complete their work and tasks. This finding is also in agreement with Pathak and Das (2003) who have indicated that the managers and the supervisors with. The results have significantly realistic guiding and enlightenment in management as well.

The findings extend previous research in several ways. Research recently revealed that abusive supervision has a significant negative impact on the attitudes, well-being, and behavior of employees $[9,16]$. Here, we argued that employees will not necessarily react negatively toward an abusive supervisor. That is, we reasoned that there are boundary conditions to the reactions of employees toward an abusive supervisor. More specifically, it was put forward that as employees identify with their organization, they are expected to show weaker negative reactions to an abusive supervisor in terms of perceptions of cohesion and gossiping since organizational identification has a buffering effect on followers' negative reactions to abusive supervision.

\section{Limitations and Recommendations}

This study was conducted by using a multi-source survey where both employees' responses and those of their supervisors were assessed. Such a multi-source design has been argued to be able to reduce common method bias [11]. This signifies that employees and supervisors are less likely to bias the relationship between variables of interest due to social desirability tendencies. However, this research only partially assessed ratings from multiple sources. That is, supervisors rated employees' tendency to gossip, but employees rated perceived cohesion. Hence, the findings with regard to perceived cohesion might still have been subject to common-method bias. Nevertheless, given the consistency in results and as common-method bias has been shown to decrease the sensitivity of tests of moderation, we are confident that common-method bias might be of lesser concern. A second limitation of our study concerns the low levels of abusive supervision reported in our sample (mean = 1.81). However, as stated by Harris et al. (2007), this finding is in line with previous research revealing levels of abusive supervision ranging from low, such as 1.26 [14] and 1.38 [13], to high, such as 2.06 [15] and 2.70 [3].

Moreover, as we were able to reveal a significant interaction effect between abusive supervision and organizational identification for both perceived cohesion and tendency to gossip, we feel confident that these low levels of abusive supervision are of little concern for data analysis. Finally, our design did not allow us to make causal inferences because of the cross-sectional nature of the data. It may well be that employee' perceived cohesion and tendencies to gossip set the stage for abusive supervision to arise. However, prior longitudinal research showed that abusive supervision is the antecedent of many negative employee outcomes $[2,6]$.

Hence, previous theorizing does support our findings, which provide some confidence in the hypothesized direction. Estimation of clustered data might potentially lead to biased estimates of standard errors. Besides, with the exception of team task performance based on ratings by the HR department, data on the other variables will be based on self-reports, suggesting the possibility of method variance. However, common method variance has been considered to be less of an issue in moderated regression [10]. For these reasons, the results may substantive and not attributable to common method variance. In addition, the effective data is difficult to collect and the sample size may relatively small. Future research should ascertain the external validity of the findings reported here in multiple organizations or in other parts of China. 


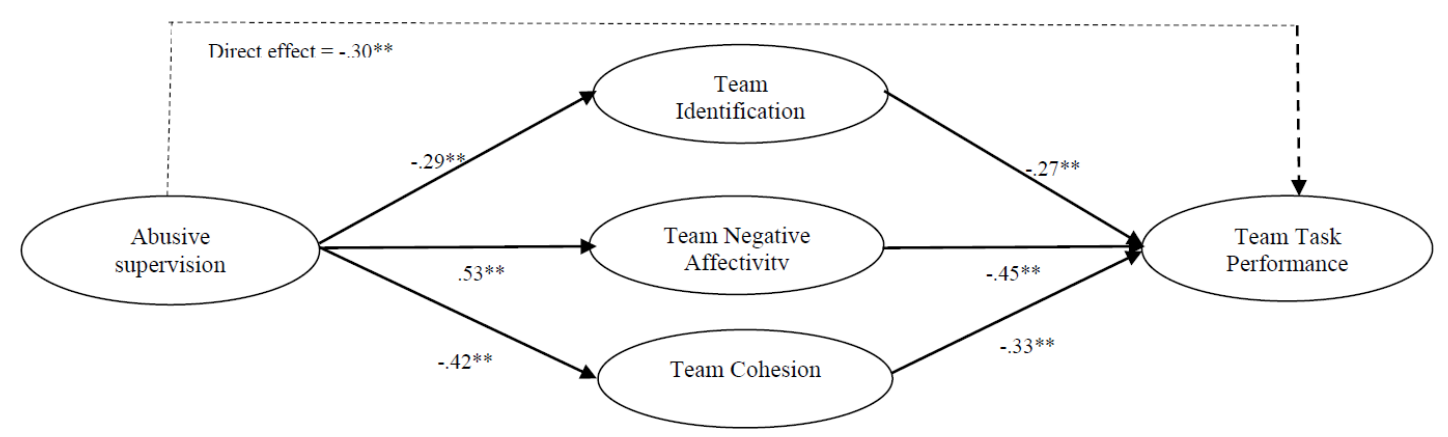

Fig.1 Results of Structural Equation Modeling on the Mediating Effect

\section{References}

[1] Archer, J., \& Coyne, S. M. (2005). An integrated review of indirect, relational, and social aggression. Personality and Social Psychology Review, 9, 212-230.

[2] Aryee, S., Chen, Z. X., Sun, L., \& Debrah, Y. A. (2007). Antecedents and outcomes of abusive supervision: Test of a trickle-down model. Journal of Applied Psychology, 92, 191-201.

[3] Bamberger, P. A., \& Bacharach, S. B. (2006) Abusive supervision and subordinate problem drinking: Taking resistance, stress and subordinate personality into account. Human Relations, 59,723-752.

[4] Cheung, G. W., \& Rensvold, R. B. (2002). Evaluating goodness-of-fit indexes for testing measurement invariance. Structural Equation Modeling, 9(2), 233-255.

[5] Harris, K. J., Harvey, P., \& Kacmar, K. M. (2011). Abusive supervisory reactions to coworker relationship conflict. The Leadership Quarterly (5), 1010.

[6] Harris, K. J., Kacmar, K. M., \& Zivnuska, S. (2007). An investigation of abusive supervision as a predictor of performance and the meaning of work as a moderator of the relationship. The Leadership Quarterly, 18, 252-263.

[7] Hoobler, J. M., \& Brass, D. J. (2006). Abusive supervision and family undermining as displaced aggression. Journal of Applied Psychology (5), 1125.

[8] Medsker, G. J., Williams, L. J., \& Holahan, P. J. (1994). A review of current practices for evaluating causal models in organizational behavior and human resources management research, 439.

[9] Mitchell, M. S., \& Ambrose, M. L. (2007). Abusive Supervision and Workplace Deviance and the Moderating Effects of Negative Reciprocity Beliefs. Journal of Applied Psychology, 92(4), 1159-1168.

[10] Pierce, J. L., Gardner, D. G., Dunham, R. B., \& Cummings, L. L. (1993). MODERATION BY ORGANIZATION-BASED SELF-ESTEEM OF ROLE CONDITION--EMPLOYEE RESPONSE RELATIONSHIPS. Academy of Management Journal, 36(2), 271-288.

[11] Podsakoff, P. M., MacKenzie, S. B., Lee, J.-Y., \& Podsakoff, N. P. (2003). Common method biases in behavioral research: a critical review of the literature and recommended remedies. Journal of Applied Psychology (5), 879.

[12] Schumacker, R. E., \& Lomax, R. G. (2004). A beginner's guide to structural equation modeling 2nd ed. United States of America: Lawrence Erlbaum Associates.

[13] Tepper, B. J. 2000. Consequences of abusive supervision. Academy of Management Journal, 43: $178-190$. 
[14] Tepper, B. J., Duffy, M. K., Hoobler, J. M., \& Ensley, M. D. 2004. Moderators of the relationship between coworkers' organizational citizenship behavior and fellow employees' attitudes. Journal of Applied Psychology, 89: 455-465.

[15] Tepper, B. J., Henle, C. A., Lambert, L. S., Giacalone, R. A., \& Duffy, M. K. (2008). Abusive supervision and subordinates' organization deviance. Journal of Applied Psychology (4), 721.

[16] Zellars, K. L., Tepper, B. J., \& Duffy, M. K. 2002. Abusive supervision and subordinates' organizational citizenship behavior. Journal of Applied Psychology, 86: 1068-1076. 